\title{
Polymorph selection and process intensification in a continuous crystallization-milling process: A case study on L-glutamic acid crystallized from water
}

DOI:

10.1021/acs.oprd.8b00420

\section{Document Version}

Accepted author manuscript

Link to publication record in Manchester Research Explorer

Citation for published version (APA):

Köllges, T., \& Vetter, T. (2019). Polymorph selection and process intensification in a continuous crystallizationmilling process: A case study on L-glutamic acid crystallized from water. Organic Process Research \& Development. https://doi.org/10.1021/acs.oprd.8b00420

Published in:

Organic Process Research \& Development

\section{Citing this paper}

Please note that where the full-text provided on Manchester Research Explorer is the Author Accepted Manuscript or Proof version this may differ from the final Published version. If citing, it is advised that you check and use the publisher's definitive version.

\section{General rights}

Copyright and moral rights for the publications made accessible in the Research Explorer are retained by the authors and/or other copyright owners and it is a condition of accessing publications that users recognise and abide by the legal requirements associated with these rights.

\section{Takedown policy}

If you believe that this document breaches copyright please refer to the University of Manchester's Takedown Procedures [http://man.ac.uk/04Y6Bo] or contact uml.scholarlycommunications@manchester.ac.uk providing relevant details, so we can investigate your claim.

\section{OPEN ACCESS}


This document is confidential and is proprietary to the American Chemical Society and its authors. Do not copy or disclose without written permission. If you have received this item in error, notify the sender and delete all copies.

\section{Polymorph selection and process intensification in a continuous crystallization-milling process: A case study on L-glutamic acid crystallized from water}

\begin{tabular}{|r|l|}
\hline Journal: & Organic Process Research \& Development \\
\hline Manuscript ID & op-2018-004209.R1 \\
\hline Manuscript Type: & Full Paper \\
\hline Complete List of Authors: & $\begin{array}{l}\text { Köllges, Till; University of Manchester, School of Chemical Engineering } \\
\text { and Analytical Science } \\
\text { Vetter, Thomas; University of Manchester, School of Chemical } \\
\text { Engineering and Analytical Science }\end{array}$ \\
\hline & \\
\hline
\end{tabular}

\section{SCHOLARONE Manuscripts}




\title{
Polymorph selection and process
} intensification in a continuous

\author{
crystallization-milling process: A case study \\ on L-glutamic acid crystallized from water \\ Till Köllges and Thomas Vetter*
}

School of Chemical Engineering and Analytical Science, The University of Manchester, Manchester, UK

E-mail: thomas.vetter@manchester.ac.uk

Phone: +44 1613064370 


\section{For Table of Contents Only}

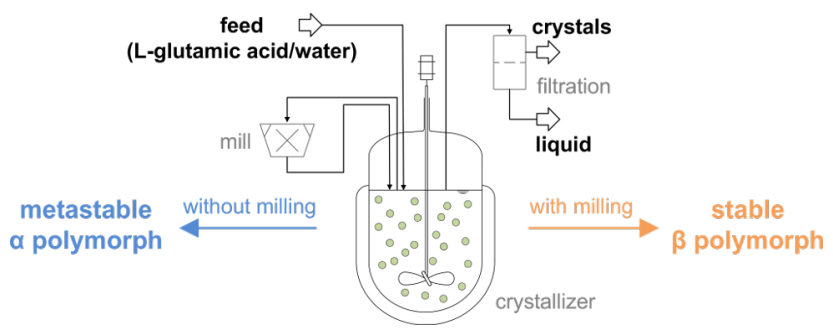




\begin{abstract}
The continuous crystallization of L-glutamic acid from water is studied in a single stage mixed suspension mixed product removal crystallizer that is coupled to a milling loop. We show that the stable $\beta$ polymorph can be obtained in the presence of milling at operating conditions that would lead to the metastable $\alpha$ polymorph without milling. The effect is first shown through a series of experiments carried out at different residence times, feed concentrations and in the absence/presence of milling. The experimental observations are rationalized through the use of a population balance equation model. We conclude that the observed effects result from fines generation and the corresponding increase in crystal surface area. Using the model, we obtain a map of polymorphic outcomes and process productivity in dependence of operating conditions. It is shown that the combined milling/crystallization process exhibits higher productivity and an enlarged region of operating conditions where the stable polymorph of L-glutamic acid can be reliably obtained in comparison to a conventional crystallization process.
\end{abstract}

Keywords: continuous crystallization; polymorphism; process intensification; population balance model. 


\section{Introduction}

A large number of substances can exist in multiple solid forms (e.g., amorphous structures, polymorphs, co-crystals, solvates). ${ }^{1-3}$ In industrial manufacturing generating a desired solid form reliably and robustly is of key importance, because the different solid forms can differ substantially in their solubility, mechanical properties, and in the case of pharmaceuticals, bioavailability. In the pharmaceutical industry, apart from being a regulatory requirement, exploring the solid state landscape is not only important to avoid the appearance of an unexpected form during manufacturing ${ }^{1}$, but also to protect intellectual property. ${ }^{2}$ In terms of manufacturing, however, one typicallly prefers a form that is solvent-free and is stable at process and storage conditions. ${ }^{4}$

Once the desired solid form is selected, a tailored crystallization process can be developed to manufacture it on the scale required. The arguably simplest way to access the most stable polymorph in a batch crystallization process is by seeding with crystals of the stable form and then growing them by creating supersaturation, e.g., through cooling or antisolvent addition. The supersaturation generation is typically carried out gently. ${ }^{4,5}$ The aim of this strategy is to keep the process below the solubility of any metastable forms, therefore eliminating the possibility of forming crystals of these forms. The red dashed trajectory shown in Figure 1 (left) illustrates this for L-glutamic acid (LGA) crystallized from water, the model system used in this work. Since LGA crystallizes in two polymorphs that are monotropically related, this processing strategy amounts to keeping the process between the solubility lines of the metastable $\alpha$ polymorph and the stable $\beta$ polymorph. The size distribution can be controlled well by selecting the size and amount of seed material. If seeding with the stable polymorph cannot be achieved, an unseeded batch crystallization can be performed. If the nucleation and growth kinetics of the metastable polymorph are faster than the kinetics of the stable polymorph, the metastable polymorph forms at the start of the process, which undergoes a solution mediated polymorph transformation towards the stable polymorph if sufficient time is provided. ${ }^{6-10}$ An example process trajectory for LGA 
Figure 1: (left) Phase diagram of L-glutamic acid in water ${ }^{12,13}$ with exemplary process trajectories: polythermal seeded batch crystallizer/seeded plug flow crystallizer (red dashed line); unseeded isothermal solution-mediated polymorph transformation (purple) and a single stage mixed suspension mixed product removal crystallizer (green). (right) Evolution of solution and solid composition in the unseeded isothermal solution-mediated polymorph transformation at $45^{\circ} \mathrm{C}$; the bottom shows the plug flow crystallizer analogy. (modified from Cornel et al. ${ }^{9}$ ).

Continuous processes have considerable advantages over batch processes, such as steady 
state operation leading to higher reproducibility, higher process efficiency, and the potential for lower capital and operational costs ${ }^{14-20}$. Theoretically, the processing strategies employed in batch crystallizers can be directly applied to continuous flow crystallizers if they are operated in a flow regime that exhibits no (or negligible) back-mixing, i.e., they are operated under plug flow conditions. In such plug flow crystallizers (PFCs), the time a fluid element has spent traveling through the crystallizer is the ratio between axial position of the fluid element and the flow velocity. Therefore, once a PFC has reached steady state operation, its length coordinate becomes equivalent to the time coordinate in a batch crystallizer (this is illustrated in Figure 1 (right) at the bottom). While several promising approaches have been developed in the recent past to achieve (near) plug flow in tubular crystallizers ${ }^{21-28}$, the approaches are not (yet) widely available in manufacturing environments. Alternatively, continuous crystallization processes can be carried out in ubiquitously available stirred vessels under complete back-mixing, referred to as mixed suspension mixed product removal crystallizers (MSMPRCs) where both feed and product streams are continuously added/withdrawn to/from a well-mixed (stirred) vessel ${ }^{16,19,20,29-31}$. In a single stage MSMRPC operated at steady state, only a few operating variables remain: the crystallizer temperature, the feed concentration, as well as the residence time of the crystallizer. Portrayed in the phase diagram, Figure 1 (left), the steady state of an MSMPRC operated at $25^{\circ} \mathrm{C}$ (point B) is located on the green vertical line connecting the feed conditions (point A) and the solubility of the stable polymorph. The exact position on this line results from the interplay of residence time and crystallization kinetics: short residence times lead to steady states close to point A, while long residence times lead to steady states closer to the solubility of the stable polymorph. Steady states between the solubility lines of the polymorphs yield pure stable polymorph reliably (thermodynamic control), while the polymorphic composition for steady states above the solubility line of the metastable polymorph depends on the crystallization kinetics of both polymorphs. However, it should be noted that running a process under such conditions may still reliably yield pure polymorphs (also the stable one) ${ }^{11,32,33}$. 
Previous studies on polymorphic systems conducted in MSMPRCs have shown how operating conditions and the number of stages affect the yield and the polymorphic form obtained. Notably, Lai et al. studied the crystallization of LGA in a single MSMPRC ${ }^{11}$ and p-aminobenzoic acid in a multi stage MSMPRC system ${ }^{32}$. Crucially, their studies have shown the feasibility of obtaining polymorphically pure products from such systems. For instance, it has been shown that the metastable form of LGA can be reliably crystallized from an MSMPR crystallizer operated at high feed concentration and low residence time ${ }^{11}$. However, the stable polymorph could only be crystallized at combinations of high temperature and short residence time (which limits yield, because of a higher solubility) or at low temperatures with (very) long residence times (which results in poor process productivity). In a seminal contribution to the field, Farmer et al. ${ }^{33}$ successfully elucidated the interplay between crystallization kinetics (nucleation and growth of the different polymorphic forms), operating conditions and the polymorphic form obtained in a single stage MSMPRC, thus explaining and generalizing the results reported by Lai et al. ${ }^{11,32}$ and others ${ }^{34}$. Ultimately, their thorough steady state and stability analysis allows to "dial in" a desired polymorph by altering the processing conditions of an MSMPRC in a targeted manner.

Motivated by the above findings, we here present a study on a single stage MSMRPC process that is coupled to a milling loop. We choose to include milling in our processing strategy, because it increases the surface area of particles present in the crystallizer and allows us to tune the rate at which small particles are formed. We thus expect that such a process arrangement will act as a means for process intensification, i.e., that higher productivities are achievable in the combined crystallization-milling process when compared with a process utilizing crystallization alone. Furthermore, since milling alters the relative rates of particle generation and crystal growth of both polymorphs, we will investigate the impact of milling on the polymorphic composition obtained from the process. To this end, we investigate the start up and steady state behavior of the combined milling-crystallization process for the model substance L-glutamic acid crystallized from water under different process conditions 
(feed concentration, residence times, with and without milling) using a process model, as well as a series of experiments. In the remainder of this article, we first describe the experimental setup in detail, followed by a description of the process model. We then rationalize the process behavior using the model and proceed to analyze the experimental results. Finally, the conclusions of this work are presented.

\section{Materials and Methods}

\subsection{Materials}

L-glutamic acid (LGA) was purchased from Acros Organics with $>99 \%$ purity and used as received. The two known LGA polymorphs exist in a monotropic system, i.e., the $\alpha$ polymorph $^{35}$ (CCDC identifier: LGLUAC03) is the metastable form at all temperatures and grows as compact prismatic crystals, while the $\beta$ polymorph $^{36}$ (CCDC identifier: LGLUAC) is the stable form and grows as needle-like crystals. Solubility data (cf. Figure 1) ${ }^{12,13}$ and kinetics for nucleation and crystal growth for both polymorphic forms have been well characterized multiple times under different experimental circumstances. ${ }^{7,9,11,37-40}$ Water of Type 1 from a Milli-Q Ultrapure Water System was used as the solvent.

\subsection{Experimental setup}

Continuous crystallization experiments were carried out in a setup, schematically depicted in Figure 2, consisting of a $10 \mathrm{~L}$ feed tank and a $500 \mathrm{~mL}$ crystallizer. Both vessels are jacketed glass reactors, equipped with temperature probes, reflux condensers and stirred by a four blade anchor $(10 \mathrm{~L}$ tank) or pitched blade $(500 \mathrm{~mL}$ crystallizer $)$ stirrer. A rotor stator suspension mill (magicLAB with MK module, IKA Werke G.m.b.H., Staufen, Germany; operated at a rotor frequency $\omega=3000 \mathrm{rpm}$ when milling was employed) is connected in a loop to the $500 \mathrm{~mL}$ crystallizer and serves as a means for crystal breakage.

Three thermostats (Ministat 230cc, Huber, Offenburg, Germany) were used to control 


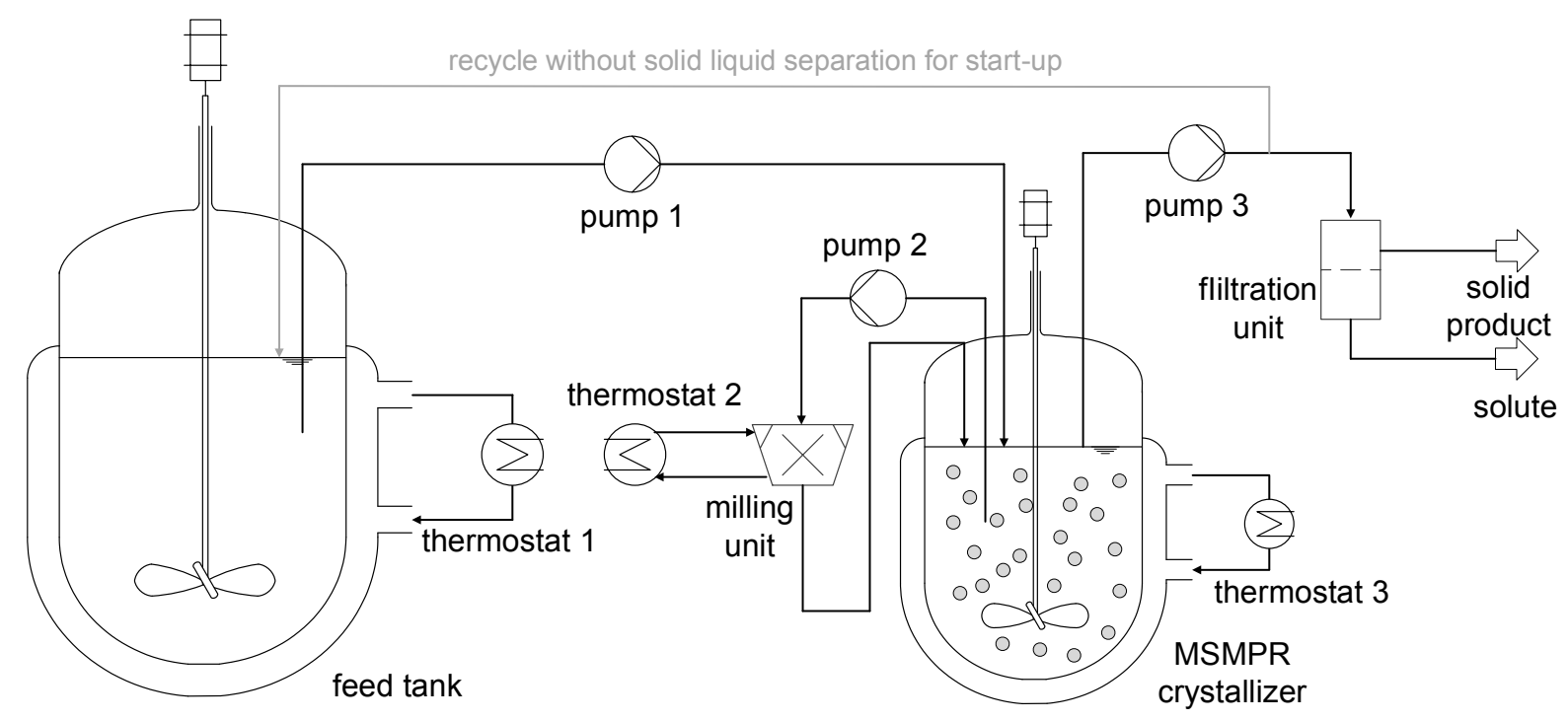

Figure 2: Schematic representation of the experimental setup used in this work.

the temperature of the rotor stator mill, the crystallizer, and the feed tank. In the continuous crystallization experiments detailed below, the feed tank was operated at $65^{\circ} \mathrm{C}$ and the 500 $\mathrm{mL}$ crystallizer and the mill were operated at $25^{\circ} \mathrm{C}$. In order to avoid undesired crystallization in the feed tube leading from the $10 \mathrm{~L}$ tank to the $500 \mathrm{~mL}$ crystallizer, a custom-built tube-in-tube heat exchanger consisting of $1 / 4$ " in $1 / 2$ " transparent PTFE tubing was employed. The heating fluid exiting thermostat 3 is split to pass through the tube-in-tube heat exchanger (in counter-current operation) and the jacket of the $10 \mathrm{~L}$ tank in parallel. Operation in this way ensures undersaturated conditions in the whole feed tube and the feed tank. Three Peristaltic pumps (L/S masterflex, ColeParmer, Illinois, USA) are used to transport solution/suspension throughout the setup (cf. Figure 1). They are fitted with flexible ColeParmer ChemDurance tubing in the pump head section; elsewhere transparent PTFE tubes $\left(1 / 4^{\prime \prime}\right)$ are used. With the crystallizer volume of $500 \mathrm{~mL}$ and residence times between 15 minutes and 2 hours, it was found that a continuous flow (i.e. a constant feed flow rate of $4-33 \mathrm{~mL} \mathrm{~min}{ }^{-1}$ ) of the product suspension is problematic. Cold wall temperatures of the tube and residual supersaturation lead to nucleation, encrustation and subsequent clogging, as well as insufficient transport of the suspension out of the crystallizer, due to size classification caused by faster settling of larger particles than the in-tube flow speed. To solve this 
asynchronous periodic flow operation ${ }^{41}$ of the pumps with a flow rate of $150 \mathrm{~mL} \mathrm{~min}{ }^{-1}$ in intervals of $120 \mathrm{~s}$ was introduced. In addition to that the tubes are emptied after each step to avoid particle settling in the product withdrawal tube and encrustation in the feed tube. The inlet of the product withdrawal tube is mounted to ensure the nominal operating volume of $500 \mathrm{~mL}$ in the crystallizer. As analyzed in detail in Su et al. ${ }^{41}$, periodic flow operation can lead to fluctuations in the crystallizer concentration, as well as temperature. However, for the short intervals used here (in comparison to the residence times) only minor fluctuations in temperature were observed (cf. Figure 3), which we deemed to be negligible. The flow rate through the mill (pump 2) is set at $150 \mathrm{~mL} \mathrm{~min}{ }^{-1}$. The cycling of the suspension through the mill was unproblematic for the continuous crystallization experiments reported below, i.e., no additional control measures were necessary.

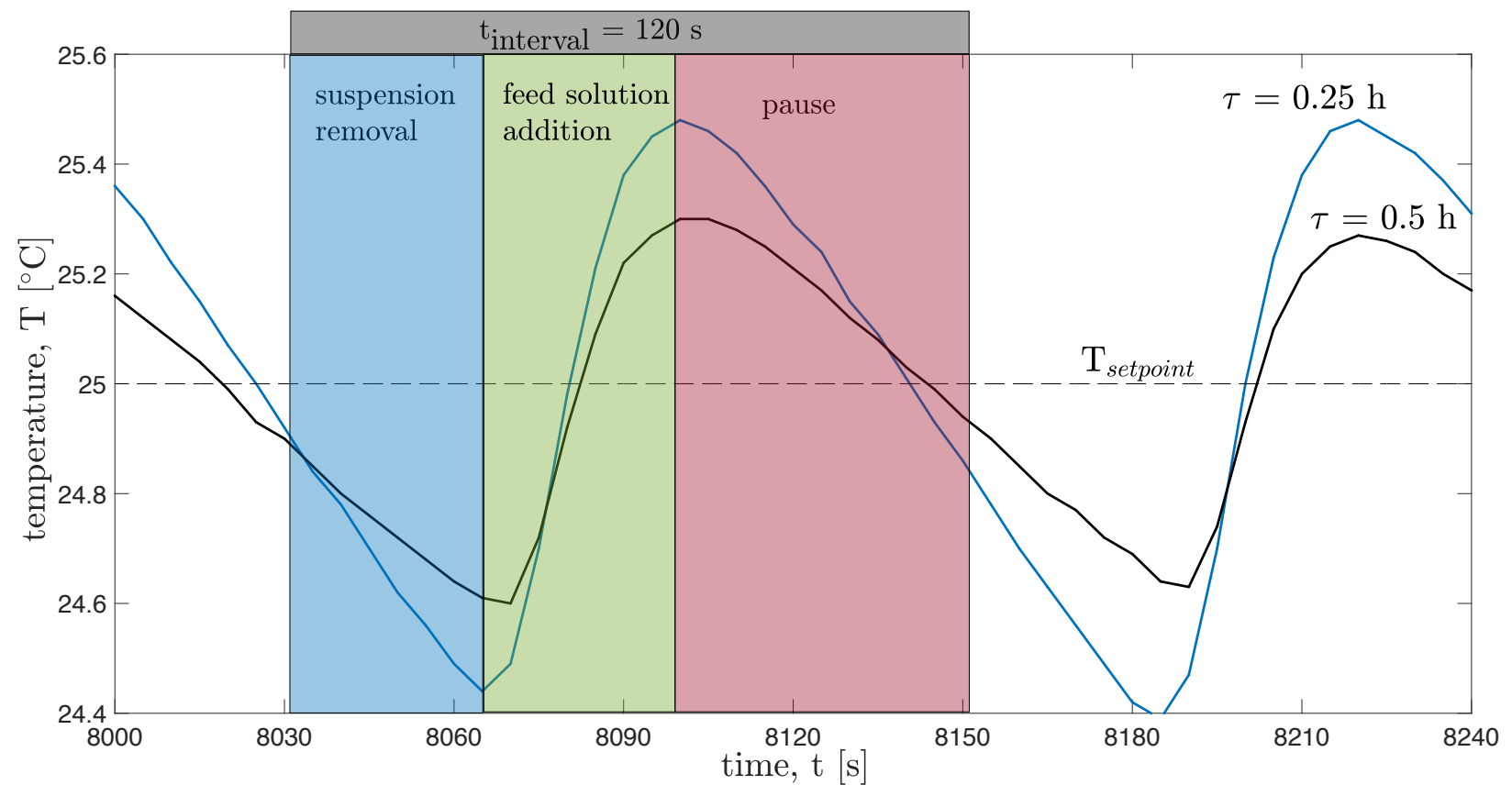

Figure 3: Temperature fluctuations in the crystallizer due to periodic flow exemplified on parts of two experiments carried out at a feed concentration of $20 \mathrm{~g} \mathrm{~kg}^{-1}$ and residence times of $\tau=0.25 \mathrm{~h}$ and $\tau=0.50 \mathrm{~h}$. 


\subsection{Generation of seed crystals}

Analogous to previous works ${ }^{37}$ seed crystals of the $\alpha$ polymorph were obtained by fast cooling crystallization. To this end, a clear solution of LGA in water with a concentration of 48 $\mathrm{g} \mathrm{kg}^{-1}$ was cooled to $45^{\circ} \mathrm{C}$ with a cooling rate of $1.5^{\circ} \mathrm{C} \mathrm{min}^{-1}$. Upon reaching this temperature, a burst of nucleation and crystal growth occurs. The crystals were then isolated by Büchner filtration, washed with cold water and subsequently dried. Powder X-ray diffraction confirmed the generated crystals to be the metastable $\alpha$ polymorph. The as received LGA from Acros was identified to be of the $\beta$ polymorph and hence used as $\beta$ seeds without further modification.

\subsection{Analytical Methods}

In order to track the liquid composition in the crystallizer, we explored the use of in situ process analytical technology (PAT), namely attenuated total reflectance Fourier transformation infrared (ATR-FTIR) spectroscopy. However, we found this to be challenging for the experimental conditions reported in this article, because the in situ probes were continuously affected by crystals growing on them (presumably caused by long term exposure to the supersaturated conditions in the continuous crystallization experiments). Despite numerous efforts (heated probes, repeated cleaning, etc.) the problem could not be avoided consistently. Instead, off-line samples were taken to track the polymorphic composition through powder X-ray diffraction, the solute concentration by gravimetric measurements, as well as to gather size and shape information by optical microscopy. Suspension samples of $25 \mathrm{~mL}$ were drawn directly from the crystallizer at specific time intervals. The suspension samples were then filtered using a preheated Büchner funnel and flask. The solids were dried in an oven at $65^{\circ} \mathrm{C}$ for 2 days and their powder X-ray diffraction patterns were measured. The powder samples were ground using pestle and mortar and then placed on a "zero/low background" Si wafer disc. All powder XRD diffraction measurements were performed on a PANalytical X'Pert - PRO theta-theta diffractometer. Data was collected from 3 to $90^{\circ}$ 
$2 \Theta$ in $0.02^{\circ}$ steps with an acquisition time of two seconds per step. In order to determine the ratio between polymorphs $\alpha$ and $\beta$ from such samples, a calibration was conducted (see supporting information for details). The solution concentration was determined by gravimetric measurements. Approximately $3 \mathrm{~mL}$ of solution collected from the Büchner funnel were transferred into a glass vial using a pre-heated syringe and immediately weighed. The vials were left in an oven to dry at $65^{\circ} \mathrm{C}$ for 2 days and subsequently weighed again. Microscopy pictures of dry crystal samples were taken on a Zeiss Axioplan Optical Microscope equipped with an Infinity 1 CMOS digital camera.

\section{Process Model}

In order to describe the evolution of the particle size distributions of both polymorphs in the crystallizer, the population balance equation (PBE) framework ${ }^{42,43}$ is used and coupled to a material balance for the concentration of LGA in the liquid phase. Here, we assume that the crystals can be described with a single characteristic length, $L$, and further proceed to model the combination of crystallizer and mill (cf. Figure 1) as a single processing unit, i.e., we act as if crystal breakage is induced directly in the crystallizer. The latter simplification is justified, because the flow rate through the mill and its operational parameters (i.e., its rotation speed) are kept constant in all experimental work and because the temperature of the mill and crystallizer are independently controlled to the same value. Thus, two PBEs (one for each polymorph) and one material balance are required in the model; in contrast to the alternative (modelling the crystallizer and mill separately), this roughly halves the computational effort required to solve the resulting process model. The PBEs account for 
crystal growth, nucleation, as well as crystal breakage and are formulated as:

$$
\begin{aligned}
\frac{\partial n_{i}(L, t)}{\partial t}= & -G_{i} \frac{\partial n_{i}(L, t)}{\partial L} \\
& +\int_{L}^{\infty} K_{i}(\lambda) d_{i}(\lambda, L) n_{i}(\lambda, t) \mathrm{d} \lambda-K_{i}(L) n_{i}(L, t) \\
& -\frac{Q n_{i}(L, t)}{V} \quad \text { with } \quad i \in\{\alpha, \beta\}
\end{aligned}
$$

where $n_{i}(L, t)$ is the particle size distribution of polymorph $i$, so that $n_{i}(L, t) \mathrm{d} L$ is the number of crystals per volume of suspension with characteristic lengths between $L$ and $L+\mathrm{d} L$ (it therefore has units of $\left.\left[\# / \mathrm{m}^{-4}\right]\right) . \quad t$ is time, $G_{i}$ is the supersaturation dependent crystal growth rate, $K_{i}$ is the crystal breakage rate, and $d_{i}$ is the size distribution of fragments generated when breaking a crystal of a specified size. The first term on the right hand side of Equation (1) therefore represents crystal growth and the second and third term represent the appearance and disappearance of crystals due to breakage, respectively. The last term represents the crystals moving from the crystallizer/mill vessel to the filtration unit, which is expressed through the volume flow rate of that stream $(Q)$ and the volume of suspension in the processing vessel $(V)$. The PBEs have the following initial and boundary conditions:

$$
\begin{aligned}
& n_{i}(L, t=0)=n_{0, i}(L) \\
& n_{i}(L=0, t)=\frac{J_{i}}{G_{i}} \text { for } c>c_{\star, i} \\
& n_{i}(L=\infty, t)=0 \text { for } c \leq c_{\star, i}
\end{aligned}
$$

where $n_{i, 0}$ is the size distribution of the seed crystals, $J_{i}$ is the nucleation rate, and $c_{\star, i}$ is the solubility. The PBEs are complemented by a material balance describing the evolution of the LGA concentration in the liquid phase:

$$
\frac{\mathrm{d} c}{\mathrm{~d} t}=\frac{Q\left(c_{\mathrm{in}}-c\right)}{V}-3 \sum_{i \in\{\alpha, \beta\}} k_{\mathrm{v}, i} \rho_{\mathrm{c}, i} G_{i} \int_{0}^{\infty} L^{2} n_{i} \mathrm{~d} L
$$


with initial condition $c(t=0)=c_{0}$. In Equation (3) $c_{\mathrm{in}}$ is the feed concentration, $\rho_{\mathrm{c}, i}$ is the crystal density of polymorph $i$, and $k_{\mathrm{v}, i}$ is its volumetric shape factor (so that $k_{\mathrm{v}, i} L^{3}$ is the volume of a crystal with characteristic length $L$ ).

In order to solve the PBEs the particle size coordinate was discretized and the growth/dissolution term was handled using a high resolution finite volume scheme laid out in detail elsewhere ${ }^{44}$. In this instance, the limited $\kappa=1 / 3$ scheme first introduced by Koren was employed ${ }^{45}$. The breakage terms were treated as source terms, adapting the fixed pivot technique introduced by Kumar and Ramkrishna ${ }^{46}$. The resulting set of ordinary differential equations was integrated using the ode45 function available in Matlab ${ }^{47}$.

The process model detailed in Equations (1) to (3) is used here to qualitatively describe the experimental results (in terms of solution concentration and polymorph mass ratio) obtained by running the process detailed in Figure 1 for different residence times, feed concentration and in the presence and absence of crystal breakage introduced by the suspension mill. In order to do so, the model needs to be supplied with appropriate constitutive equations. The literature proffers various expressions for the growth and nucleation rates of the $\alpha$ and $\beta$ polymorph of LGA, ${ }^{7,9,11,37-40,48}$ which were established under different experimental conditions. Here, we have used the expressions reported by Hermanto et al. ${ }^{39}$, because that work provided growth and nucleation rates for both polymorphs that were estimated from experimental data roughly covering the temperature and supersaturation range encountered in the present work. Furthermore, the kinetics were established for a model based on a single characteristic length for the particles, as in the present work. The relevant constitutive equations are reported in Table 1. From this table it is evident that the growth rates were described by power laws and the nucleation rates were assumed to result from secondary nucleation that is proportional to the third moments of the particle size distribution of the polymorphs. Furthermore, the nucleation rate of the $\beta$ polymorph includes a cross-nucleation term (i.e., $\beta$ crystals forming due to the presence of $\alpha$ crystals), where nucleation of the $\alpha$ crystals stems only from already existing $\alpha$ crystals. 
Table 1: Overview of constitutive equations used to describe the nucleation, growth and dissolution rates of the $\alpha$ and $\beta$ polymorph of L-glutamic $\operatorname{acid}^{\dagger, \#, \S, \ddagger}$.

\begin{tabular}{ll}
\hline mechanism & equation $/$ parameters \\
\hline growth rate of $\alpha$ polymorph & $G_{\alpha}=k_{\mathrm{g} \alpha, 0} \exp \left(-\frac{E_{\alpha}}{R(\theta+273)}\right)\left(S_{\alpha}-1\right)^{g_{\alpha}} \quad$ for $\quad S_{\alpha} \geq 1$ \\
& $k_{\mathrm{g} \alpha, 0}=6.540 \mathrm{~m} \mathrm{~s}^{-1}$ \\
& $E_{\alpha}=4.3088 \times 10^{4} \mathrm{~J} \mathrm{~mol}^{-1}$ \\
& $g_{\alpha}=1.859$ \\
\hline dissolution rate of $\alpha$ polymorph & $G_{\alpha}=k_{\mathrm{d} \alpha}\left(S_{\alpha}-1\right)^{g_{\alpha}}$ \\
& $k_{\mathrm{d} \alpha}=3.5006 \times 10^{-5} \mathrm{~m} \mathrm{~s}^{-1}$ \\
\hline growth rate of $\beta$ polymorph & $G_{\beta}=k_{\mathrm{g} \beta, 0} \exp \left(-\frac{E_{\beta}}{R(\theta+273)}\right)\left(S_{\beta}-1\right)^{g_{\beta, 1}} \exp \left(-\frac{g_{\beta, 2}}{S_{\beta}-1}\right)$ \\
& $k_{\mathrm{g} \beta, 0}=3.8387 \times 10^{22} \mathrm{~m} \mathrm{~s}^{-1}$ \\
& $E_{\beta}=1.7596 \times 10^{5} \mathrm{~J} \mathrm{~mol}^{-1}$ \\
& $g_{\beta, 1}=1.047$ \\
& $g_{\beta, 2}=0.778$ \\
\hline nucleation rate of $\alpha$ polymorph & $J_{\alpha}=k_{\mathrm{j} \alpha}\left(S_{\alpha}-1\right) \mu_{\alpha, 3}$ \\
& $k_{\mathrm{j} \alpha}=3.0493 \times 10^{7} \mathrm{~m}^{-3} \mathrm{~s}^{-1}$ \\
\hline nucleation rate of $\beta$ polymorph & $J_{\beta}=k_{\mathrm{j} \beta, 1}\left(S_{\beta}-1\right) \mu_{\alpha, 3}+k_{\mathrm{j} \beta, 2}\left(S_{\beta}-1\right) \mu_{\beta, 3}$ \\
& $k_{\mathrm{j} \beta, 1}=7.2826 \times 10^{6} \mathrm{~m}^{-3} \mathrm{~s}^{-1}$ \\
& $k_{\mathrm{j} \beta, 2}=4.8517 \times 10^{8} \mathrm{~m}^{-3} \mathrm{~s}^{-1}$ \\
\hline
\end{tabular}

${ }^{\dagger} \theta$ represents temperature in ${ }^{\circ} \mathrm{C}$.

\# $R$ is the gas constant.

$\S S_{i}=c / c_{\star, i}$ is the supersaturation with respect to polymorph $i$, where $c$ is the liquid phase concentration and $c_{\star, i}$ is the solubility of polymorph $i$.

$\ddagger \mu_{i, 3}=\int_{0}^{\infty} L^{3} n_{i} \mathrm{~d} L$ is the third moment of the particle size distribution of polymorph $i$. 
It is noteworthy that we have chosen to include a description of the dissolution rate for the crystals of the $\alpha$ polymorph, because we are also interested in the dynamics towards steady state under different seeding conditions. However, the choice of the dissolution rate will not affect the steady states established by the model* ${ }^{*}$ as mentioned in earlier works. ${ }^{11,33}$

In contrast to the extensive characterization effort on the growth and nucleation kinetics of both polymorphs of L-glutamic acid, there has been little work carried out on the description of crystal breakage kinetics for this system. To the authors' knowledge, the work by Salvatori and Mazzotti ${ }^{49}$ represents the only work to date in this direction and is focussed on the $\beta$ polymorph exclusively. In that work, a morphological PBE model is employed with the aim of describing size and shape changes induced by milling. In this work, we instead opt to treat crystal breakage in a simplified manner consistent with the one-dimensional PBE mentioned above. The daughter distribution, $d_{i}(\lambda, L)$, describing the number of fragments of size $L$ formed when breaking a particle of size $\lambda$ was chosen as: ${ }^{50-53}$

$$
d_{i}(\lambda, L)=3\left(2 q_{i}+1\right) L^{2}\left(\frac{2}{\lambda^{3}}\right)^{2 q_{i}+1}\left(L^{3}-\frac{\lambda^{3}}{2}\right)^{2 q_{i}}
$$

with $q_{i}=7$ in all simulations including breakage in this work. The breakage rate $K_{i}(L)$ was chosen as:

$$
K_{i}(L)=k_{\mathrm{b}, i} L
$$

with $k_{\mathrm{b}, i}=80 \mathrm{~s}^{-1} \mathrm{~m}^{-1}$. The value of this prefactor was selected to lead to qualitative agreement of the model with the experimental results presented later in this article. Combined with the residence times of the crystallizer/mill combination used in our simulation work, these functional choices and parameter choices represent reasonable breakage conditions ${ }^{54}$. For simplicity, we have assumed that crystals of both polymorphs break with the same rate and with the same daughter distribution, i.e., $k_{\mathrm{b}, \alpha}=k_{\mathrm{b}, \beta}$ and $q_{\alpha}=q_{\beta}$. The remaining material constants used in the simulations are mentioned in Table 2.

\footnotetext{
${ }^{*}$ Note that this is only true for single stage MSMPRC processes; for cascades there exist cases where the dissolution rate affects the steady state in all but the first crystallizer
} 
Table 2: Material constants for LGA used in the process model.

\begin{tabular}{lll}
\hline description & symbol & value \\
\hline crystal density of $\alpha^{35}$ & $\rho_{\mathrm{c}, \alpha}$ & $1532 \mathrm{~kg} \mathrm{~m}^{-3}$ \\
crystal density of $\beta^{36}$ & $\rho_{\mathrm{c}, \beta}$ & $1569 \mathrm{~kg} \mathrm{~m}^{-3}$ \\
volume shape factor for $\alpha^{9}$ & $\mathrm{k}_{\mathrm{v}, \alpha}$ & $\pi / 6$ \\
volume shape factor for $\beta^{9}$ & $\mathrm{k}_{\mathrm{v}, \beta}$ & 0.01 \\
\hline
\end{tabular}

\section{Results and Discussion}

\subsection{Overview}

We have investigated the MSMPR process shown in Figure 2 in terms of its start up and steady state behavior under different operating conditions with respect to the solution concentration, as well as the polymorphism of the product obtained. To this end, we have varied the residence time, the feed concentration, as well as the polymorph with which the process was seeded. We have also run the process with and without the suspension mill active. The simulation results obtained from the process model detailed above are presented first, followed by the experimental results.

\subsection{Simulation Results}

In order to investigate the start up and steady state behavior of the continuous crystallizationmilling process we have performed simulations with various operating and initial conditions, as detailed in Table 3. All simulations were carried out at a temperature of $25^{\circ} \mathrm{C}$ with initial concentrations equal to the solubility of the stable $\beta$ polymorph at this temperature, i.e., $c_{0}=8.51 \mathrm{~g} \mathrm{~kg}^{-1}$. Seeding was performed with crystals of the $\alpha$ polymorph, with crystals of the $\beta$ polymorph, or with equal masses of both polymorphs. The total seed mass was set equal to the maximum theoretical yield attainable, i.e., $m_{\text {seeds }}=V\left(c_{\text {in }}-c_{\star, \beta}\right)$, and the seed particle size distribution was specified as

$$
n_{0, i}(L)=k_{\text {seeds }, i} \exp \left(-\frac{(L-\mu)^{2}}{\sigma^{2}}\right)
$$


where $k_{\text {seeds, } i}$ was chosen to establish the seed mass as mentioned above and the mean size and standard deviation of the seed particle size distribution were chosen as $\mu=2.5 \times 10^{-4} \mathrm{~m}$ and $\sigma=5 \times 10^{-5} \mathrm{~m}$, respectively.

Table 3: Operating and initial conditions used in the process simulations. ${ }^{\dagger}$

\begin{tabular}{ll}
\hline residence time, $\tau[\mathrm{h}]$ & feed concentration, $c_{\mathrm{in}}\left[\mathrm{g} \mathrm{kg}^{-1}\right]$ \\
\hline $0.25,0.50,1.00,1.25,1.50,1.75,2.00$ & $15,20,25,30,35,40$ \\
\hline
\end{tabular}

$\dagger$ Simulations for all operating parameter combinations were carried out with and without breakage.

We first investigate the start up behavior of the process at a fixed residence time $\tau=1 \mathrm{~h}$ and a feed concentration $c_{\mathrm{in}}=20 \mathrm{~g} \mathrm{~kg}^{-1}$ when the process is seeded with the $\alpha$ polymorph, the $\beta$ polymorph, or a mixture of both polymorphs. We report the evolution of the liquid phase concentration and the mass fraction of the $\beta$ polymorph in the crystallizer in Figure 4 . When seeding with a mixture of both polymorphs (purple curves), the solution concentration (left panel) quickly increases from the initial concentration to the solubility of the $\alpha$ polymorph and the mass fraction of the $\beta$ polymorph increases (right panel), which indicates the rapid dissolution of crystals of the $\alpha$ polymorph. After this initial dissolution phase, crystals of both polymorphs grow throughout the rest of the process. The solution concentration reaches a steady state that is supersaturated with respect to both polymorphs and is lower than the inlet concentration. The mass fraction of the $\beta$ polymorph shown in the right panel decreases towards zero as time evolves, indicating that the $\beta$ crystals are washed out, i.e., the mass deposition rate on $\beta$ crystals is smaller than the mass removal rate through the outlet stream. When seeding with the $\alpha$ polymorph (red curves), the same steady state is reached and the evolution of the solution concentration exhibits similar features as in the mixed seeding case. The mass fraction of the $\beta$ polymorph steadily remains at zero, indicating that no significant nucleation and growth of the $\beta$ polymorph occurs. Conversely, when seeding with the $\beta$ polymorph (blue curves), the solution concentration approaches the inlet concentration and the mass fraction of the $\beta$ polymorph remains at one. Referring back to 
the constitutive equations reported in Table 1, one realizes that this behavior is owed to the specified nucleation rates: following Hermanto et al. ${ }^{39}$ we have assumed that the formation of new crystals proceeds exclusively through secondary nucleation (which, for the $\alpha$ polymorph, only depends on the presence of $\alpha$ crystals). Therefore, if no $\alpha$ crystals are initially present, they will never form, which creates the possibility for a different steady state to be obtained. However, this steady state is dynamically unstable, i.e., even slight deviations from it will lead to the other, dynamically stable, steady state (see Farmer et al. ${ }^{33}, 55$ for an in depth discussion). Experimentally, there is always a chance for primary nucleation to occur (even if its rate is slow) or for accidental seeding to occur, which leads to the dynamically stable steady state. For the remainder of the simulation work presented here, we therefore use mixed seeds to start up the process, so that obtaining the dynamically stable steady state is ensured.
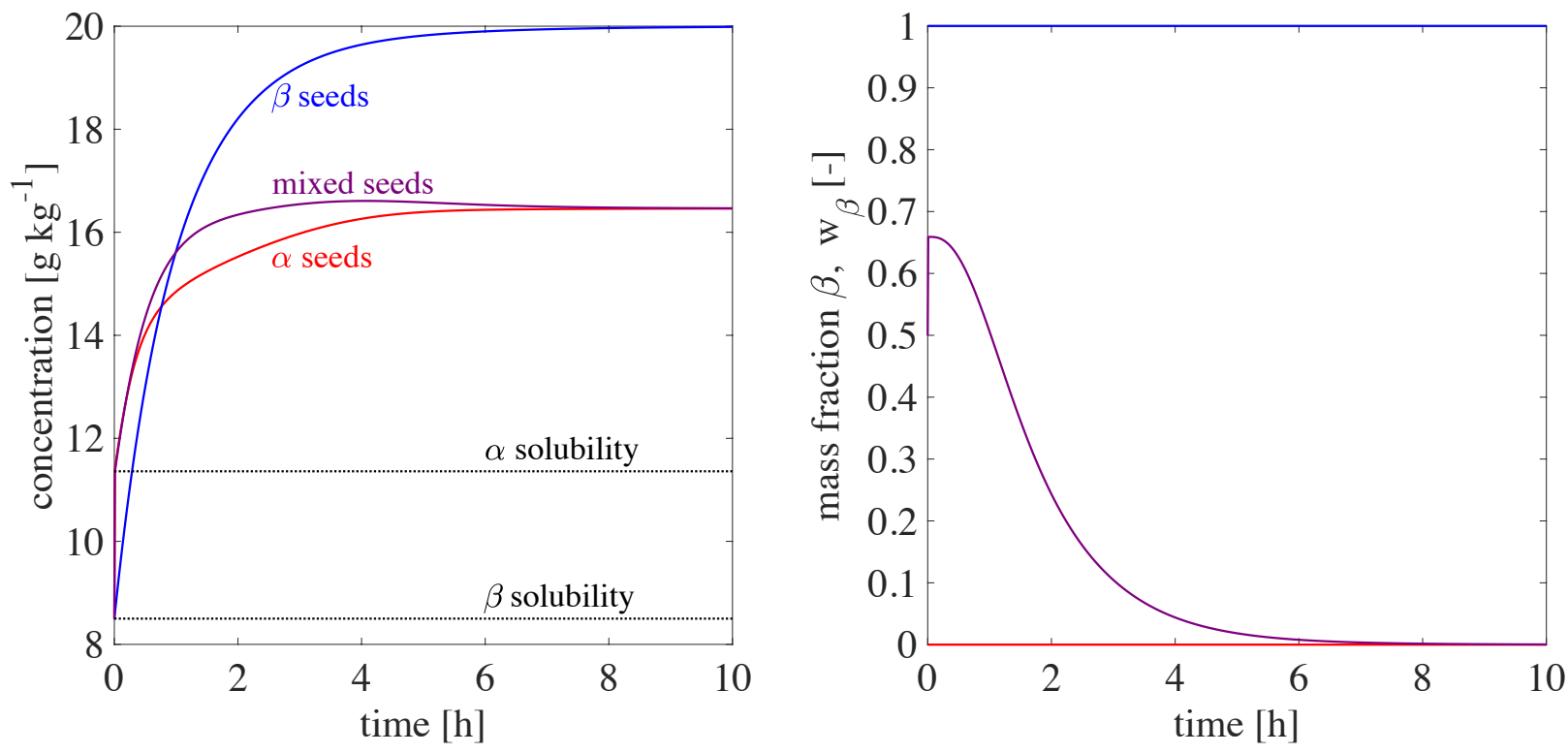

Figure 4: Start up behavior of the process with residence time $\tau=1 \mathrm{~h}$ and feed concentration $c_{\mathrm{in}}=20 \mathrm{~g} \mathrm{~kg}^{-1}$ under different seeding conditions ( $\alpha$ seeds in red, $\beta$ seeds in blue, mixed seeds in purple). (left) evolution of the solution concentration, (right) evolution of the mass fraction of the $\beta$ polymorph.

Introducing particle breakage through a suspension mill affects the particle size distribution of both polymorphs in the crystallizer and therefore affects the steady state obtained, 
as well as the transient behavior to the steady state. We exemplify this in Figure 5, where we show simulation results obtained with residence time $\tau=1.75 \mathrm{~h}$ and feed concentration $c_{\mathrm{in}}=20 \mathrm{~g} \mathrm{~kg}^{-1}$. One sees that the steady state concentration obtained with milling is lower than without milling (left panel). This can be understood by realizing that milling increases the surface area of the particles in the crystallizer. This results in an increase of the mass deposition rate (see Equation (3)) and hence a lower steady state concentration. Strikingly, the polymorph obtained at steady state switches from the metastable $\alpha$ to the stable $\beta$ polymorph once milling is employed, as can be seen from the right panel of Figure 5 . The evolution of the mass fraction of $\beta$ over time in the case without milling is similar to the case shown in Figure 4. In the case with milling, the mass fraction of $\beta$ first increases (due to the initial dissolution phase), then decreases towards 0.1 and then increases to one, i.e., pure $\beta$ polymorph. The decrease can be rationalized as the effect of breakage of both polymorphs. The growth rate for $\alpha$ is higher than for $\beta$ in this transient phase, leading to the observed decrease of the mass fraction of $\beta$ in the crystallizer. However, as the solution concentration decreases further, the growth and nucleation rates change, leading to a situation where the $\alpha$ crystals wash out slowly over time (and hence the mass fraction of $\beta$ increases). It is worthwhile to point out that this is not the effect of a solution mediated polymorph transformation; in fact, after the initial sharp increase of solution concentration at the start of the process, the solution concentration is continuously above the solubility of the $\alpha$ polymorph, i.e., the solution is supersaturated with respect to both polymorphs.

It should also be noted that the solution concentration quickly becomes close to its steady state value in the case with milling, while the mass fraction of $\beta$ still changes dramatically ${ }^{\dagger}$ Such process behavior is potentially worrying: if steady state attainment were identified using solution concentration measurements only, the process could be assumed to be at steady state prematurely. Using a single suspension sample from this "steady state" to determine the polymorph obtained from the process can then be misleading. As an example,

${ }^{\dagger}$ While not explicitly shown here, this behavior also occurs in cases without milling for some combinations of feed concentration, initial concentration, residence time and seeding strategy. 

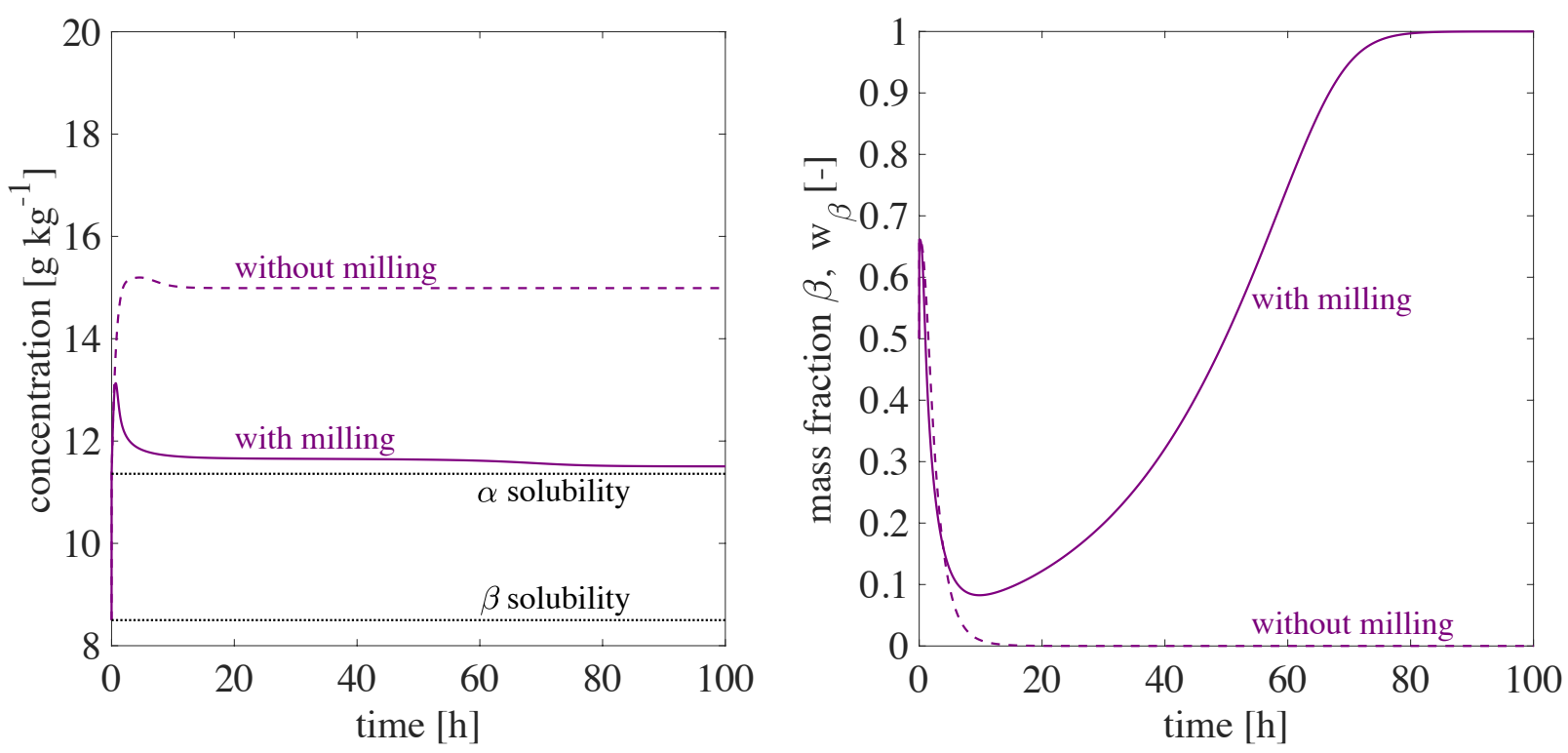

Figure 5: Start up behavior of the process with residence time $\tau=1.75 \mathrm{~h}$ and feed concentration $c_{\text {in }}=20 \mathrm{~g} \mathrm{~kg}^{-1}$ without milling (dashed lines) and with milling (solid lines). (left) evolution of the solution concentration, (right) evolution of the mass fraction of the $\beta$ polymorph.

in Figure 5 one could easily have mistaken the process to be at steady state after 20 hours when only considering solution concentration, but the mass fraction of $\beta$ would have been misidentified as $\approx 0.15$, rather than pure $\beta$ at the actual steady state.

We now consider a wider range of feed concentrations and residence times (cf. Table 3). An overview of the steady state results is reported in Figure 6 in terms of solution concentration at steady state, $c_{\mathrm{ss}}$, and the mass fraction of $\beta$ at steady state, $w_{\beta, \mathrm{ss}}$. The mass fraction of $\beta$ at steady state is reported in the top two panels in this figure, where conditions yielding the metastable $\alpha$ polymorph are shown in pale yellow and conditions yielding the stable $\beta$ polymorph are shown in black. For the cases without milling (top left panel), we can see that all residence times and feed concentrations yield the metastable $\alpha$ polymorph. For the cases with milling (top right panel), pure $\beta$ polymorph was obtained at residence times of 1.75 and 2 (and more) hours regardless of the feed concentration used (i.e., $15 \mathrm{~g} \mathrm{~kg}^{-1} \leq c_{\mathrm{in}} \leq$ $\left.40 \mathrm{~g} \mathrm{~kg}^{-1}\right)$, whereas simulations carried out at shorter residence times $(\tau \leq 1.5 \mathrm{~h})$ resulted in steady states exhibiting pure $\alpha$ polymorph. The grey area shown between $1.5 \mathrm{~h}$ and 1.75 
$\mathrm{h}$ residence time is an area where no simulations were carried out.

Focussing now on the steady state solution concentration (lower panels in Figure 6), one can see that (i) higher residence times (at a constant feed concentration) lead to lower steady state solution concentrations, (ii) the cases with milling exhibit lower steady state concentrations compared to the equivalent cases without milling, and (iii) the impact of the feed concentration on the steady state solution concentration is only visible in the case without milling at low residence times. In fact, simulations performed at the lowest feed concentration of $15 \mathrm{~g} \mathrm{~kg}^{-1}$ without milling have led to steady states with essentially no particles present, i.e., the crystal growth and nucleation rates are too low to sustain a crystal population in the crystallizer. We have also drawn white contour lines representing the productivity of the process into the lower panels, where we have calculated the productivity, $P$, as:

$$
P=\tau^{-1} \sum_{i \in\{\alpha, \beta\}} k_{\mathrm{v}, i} \rho_{\mathrm{c}, i} \int_{0}^{\infty} L^{3} n_{i} \mathrm{~d} L
$$

That is, the productivity is defined as the mass of crystals produced per volume of suspension per time. Congruent with the observation made regarding the solution concentration, the productivity is highest at low residence times and high feed concentrations and the productivity is higher for the cases with milling (at otherwise equal operating conditions). It is noteworthy that the case with milling is predicted to allow producing the stable $\beta$ polymorph at reasonable productivity values within the parameter range investigated (up to roughly $\left.15 \mathrm{~kg} \mathrm{~m}^{-3} \mathrm{~h}^{-1}\right)$.

Comparing our results to previous studies on the LGA/water system carried out in continuous crystallizers ${ }^{11,33}$, we find that our results for the case without milling are in good agreement with them (neither study investigated milling). Specifically, the experiments carried out by Lai et al. ${ }^{11}$ indicated that only the $\alpha$ polymorph is obtained at steady state in the parameter range studied in our simulations. However, in terms of the solution concentration at steady state, they have reported values ranging from 28.6 to $18.2 \mathrm{~g} \mathrm{~kg}^{-1}$ for residence 
times from 0.5 to 2 hours and a feed concentration of $40 \mathrm{~g} \mathrm{~kg}^{-1}$. While these values are higher than what we obtained in our simulations, the trend they observed is in qualitative agreement with our model results. Interestingly, the same authors concluded that residence times in excess of $17.4 \mathrm{~h}$ would be required to obtain the $\beta$ polymorph at steady state (at $25^{\circ} \mathrm{C}$ ), which would result in low process productivities. Conversely, our model results predict that the $\beta$ polymorph can be manufactured at substantially higher productivities when milling is employed. Farmer et al. ${ }^{33}$ reported extensive simulation results on the LGA/water system. Their observations regarding steady state stability, as well as the occurrence of a steady state without particles present (i.e., where initially present seed particles are washed out, as in the case mentioned above) are in excellent agreement with our own results. While we have conducted the modeling study presented in the main part of this article using the kinetics reported by Hermanto et al. ${ }^{39}$, we have additionally studied the process model using the kinetic rate equations reported by Lai et al. ${ }^{11}$ in the supplementary material. While these results are quantitatively different, they are in good qualitative agreement with the results presented here. 

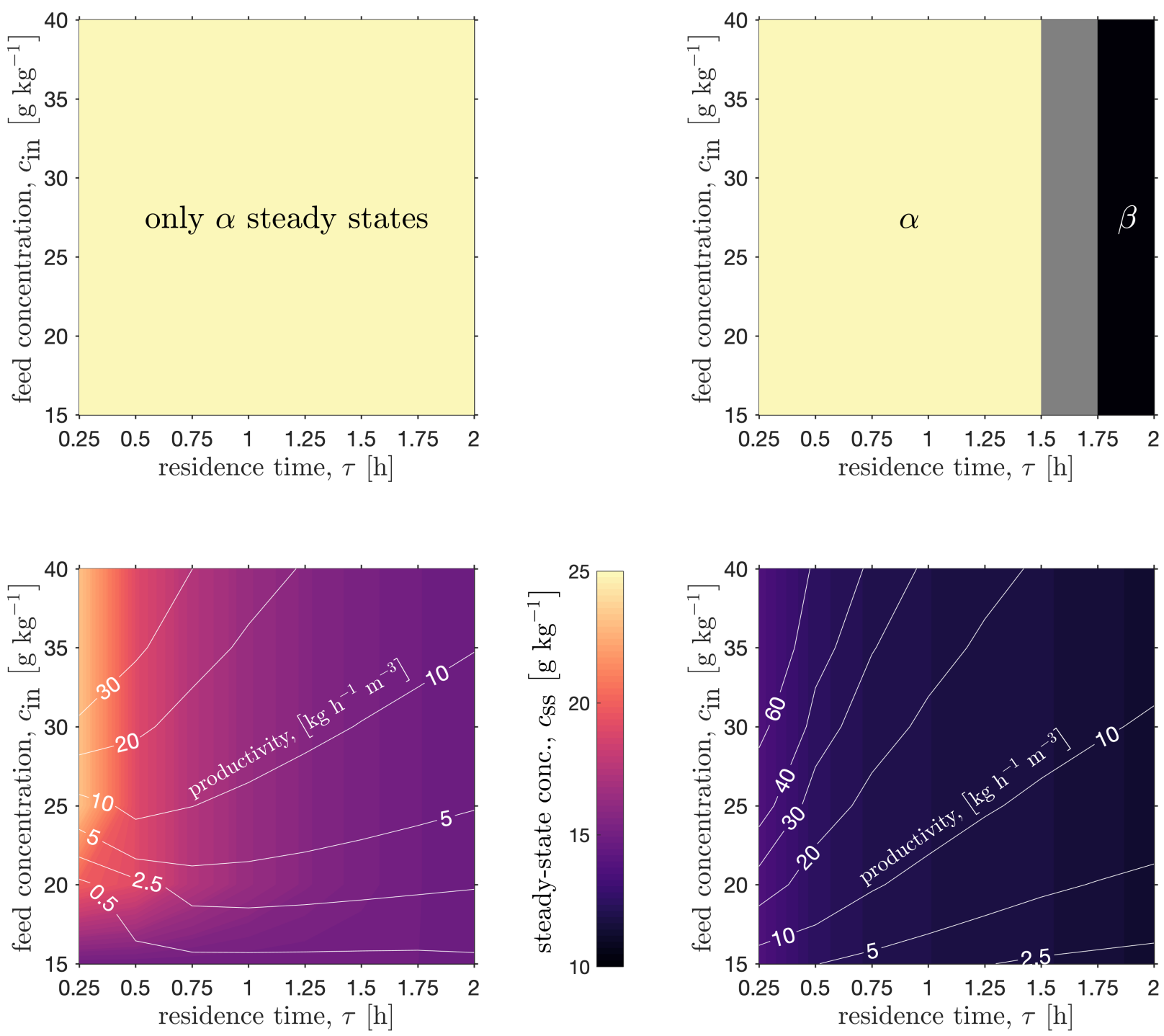

Figure 6: Mass fraction of $\beta$ polymorph (top panels) and solution concentration (bottom panels) at steady state obtained from process simulations that were run with a range of residence times and feed concentrations (cf. Table 3). (Left panels) without milling; (right panels) with milling. In the top panels conditions where the $\alpha$ polymorph was obtained are shown in pale yellow, whereas conditions yielding the $\beta$ polymorph are shown in black (no simulations were performed in the grey area). In the bottom panels, the colormap ${ }^{56}$ indicates the solution concentration at steady state, whereas the white contour lines indicate the productivity. 


\subsection{Experimental Results}

In this section, we strive to investigate the qualitative validity of our simulation results presented above using an experimental study. To this end, we have performed a set of experiments in the continuous MSMPR crystallizer/mill combination presented in the Materials \& Methods section with the crystallizer temperature set at $25^{\circ} \mathrm{C}$ and the other operating parameters as mentioned in Table 4 . The residence time that could be explored experimentally was limited to the range of $0.25-2 \mathrm{~h}$, because of considerations relating to the transport of suspension from the crystallizer - even when employing the intermittent pumping strategy detailed earlier in this article. The feed concentration that we could reliably explore was limited to the range of $20-30 \mathrm{~g} \mathrm{~kg}^{-1}$. Below the lower limit, very dilute suspensions resulted at steady state, which made obtaining reliable crystal samples to determine polymorphic content difficult. At feed concentrations of $40 \mathrm{~g} \mathrm{~kg}^{-1}$, which required temperatures of $>80^{\circ} \mathrm{C}$ in the feed tank to maintain a clear solution, degradation of LGA in solution was observed (see differential scanning calorimetry data reported in the supporting information). Hence, we chose an upper limit for the feed concentration of $30 \mathrm{~g} \mathrm{~kg}^{-1}$ with a feed temperature of $65^{\circ} \mathrm{C}$, where we did not observe LGA degradation for the duration of the experiments.

Table 4: Operating conditions used in the experimental study

\begin{tabular}{llll}
\hline Exp. No. & $c_{\text {in }}\left[\mathrm{g} \mathrm{kg}^{-1}\right]$ & $\tau[\mathrm{h}]$ & milling \\
\hline $1-4$ & 20 & $0.25,0.5,1,2$ & without \\
$5-8$ & 20 & $0.25,0.5,1,2$ & with \\
$9-12$ & 30 & $0.25,0.5,1,2$ & without \\
$13-16$ & 30 & $0.25,0.5,1,2$ & with \\
\hline
\end{tabular}

The process start up in our experimental study was performed from saturated solutions (with respect to the $\beta$ polymorph) into which seeding was performed. The seed amount was chosen to correspond to the maximum theoretical yield $\left(c_{\mathrm{in}}-c_{\star . \beta}\right)$, resulting in seed amounts of $11.5 \mathrm{~g} \mathrm{~kg}^{-1}$ and $21.5 \mathrm{~g} \mathrm{~kg}^{-1}$ for feed concentrations of $20 \mathrm{~g} \mathrm{~kg}^{-1}$ and $30 \mathrm{~g} \mathrm{~kg}^{-1}$, respectively. Seeding was performed with either the pure $\alpha$ or the pure $\beta$ polymorph. In 
order to distinguish results from experiments seeded with the $\alpha$ polymorph from experiments seeded with the $\beta$ polymorph, we include the subscript $\alpha$ or $\beta$ with the respective experiment number in the remainder of this article.

Focussing first on the start up behavior of the process at low residence times, we report results from experiments carried out at a residence time of $\tau=0.25 \mathrm{~h}$, both feed concentrations, with/without milling and seeded with the pure $\beta$ polymorph (i.e., experiments $1_{\beta}$, $5_{\beta}, 9_{\beta}$, and $13_{\beta}$ from Table 4$)$. The evolution of the solution concentration and the mass fraction of $\beta$ polymorph observed in these experiments is shown in Figure 7 . One can see that the solution concentration in all cases first increases rapidly, reaches a maximum and subsequently approaches a steady state value at a lower concentration (but above the $\alpha$ solubility in all cases). In agreement with our simulation study (cf. Figure 5), both the steady state concentration and the observed maximum are lower for the experiments with milling. This difference in steady state solution concentration points at an increase in productivity when milling is used, which is in agreement with our model-based study, cf. Figure 6. However, while there is qualitative agreement between simulations and experiments regarding the shape of the curves and the trends observed, the experimentally observed solution concentrations are generally lower than the ones obtained in the simulation study. Since secondary nucleation kinetics are sensitive to the hydrodynamic conditions of the crystallizer, which were not the same in the experiments reported by Hermanto et al. ${ }^{39}$ and our own experiments, a difference in nucleation kinetics is the most likely source of this discrepancy. With respect to the mass fraction of $\beta$ polymorph, the experimental data indicates that the seeded $\beta$ polymorph is quickly washed out with the mass fraction of $\beta$ approaching zero after roughly 6 residence times.

In the case of LGA the evolution of the polymorphs present in the crystallizer can also be visually observed, because the $\beta$ polymorph crystallizes in a needle-like shape, while the $\alpha$ polymorph crystallizes in a compact prismatic form. A series of microscopy pictures of experiment $5_{\beta}$, taken for samples obtained at different times throughout the process, confirms 

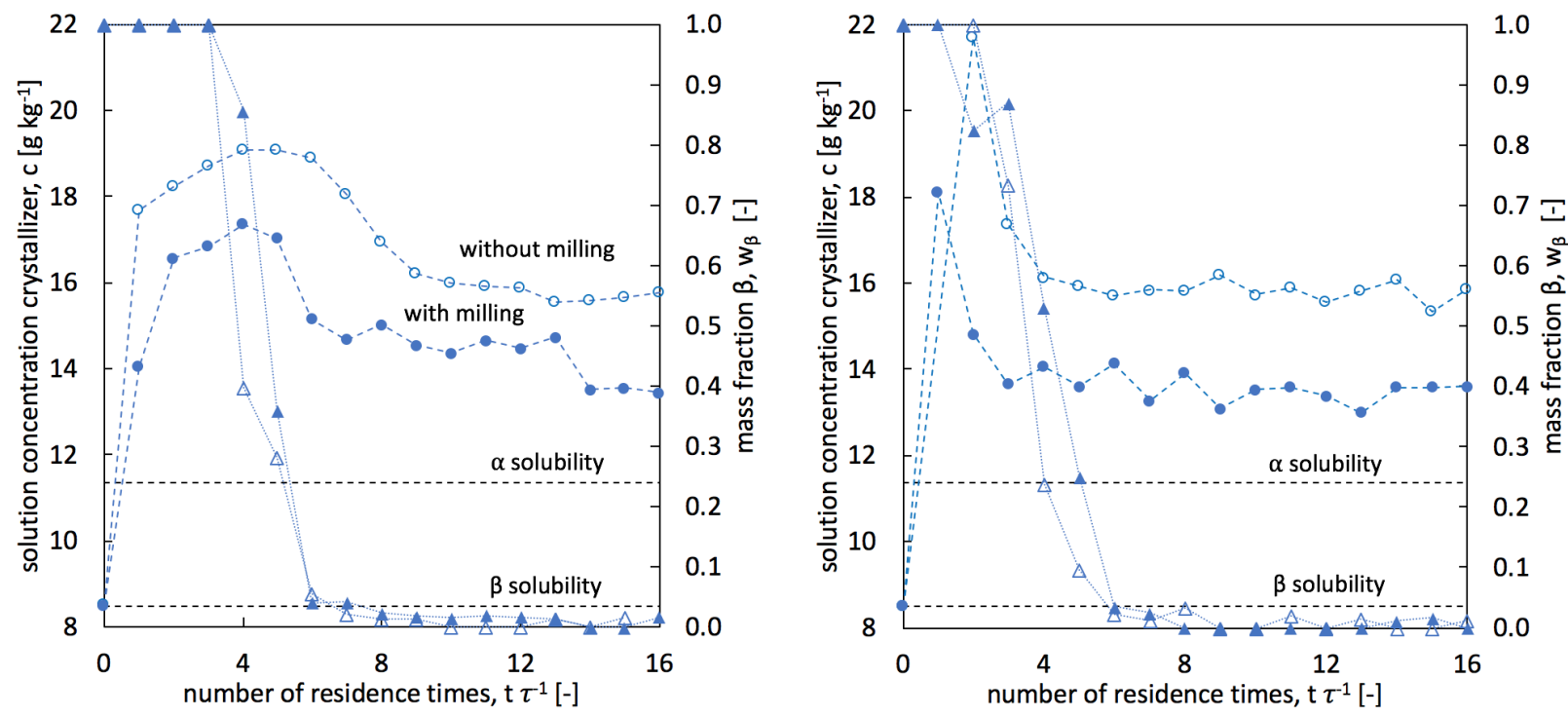

Figure 7: Evolution of solution concentration and mass fraction of $\beta$ polymorph observed for experiments conducted at a residence time $\tau=0.25 \mathrm{~h}$. (Left) Start Up of Exp. $1_{\beta}+5_{\beta}$ at $c_{\text {in }}=20 \mathrm{~g} \mathrm{~kg}^{-1}$ and (Right) of Exp. $9_{\beta}+13_{\beta}$ at $c_{\text {in }}=30 \mathrm{~g} \mathrm{~kg}^{-1}$. On the left vertical axis the solution concentrations of the experiments without milling are drawn as empty circles (o); for experiments with milling as filled circles $(\bullet)$. The mass fraction of $\beta$ polymorph is given on the right vertical axis and is drawn for the experiment without milling as empty triangles $(\triangle)$ and for the experiments with milling as filled triangles $(\boldsymbol{\Delta})$. Lines drawn to guide the eye. 
a switch from the seeded $\beta$ polymorph to the $\alpha$ polymorph (pictures shown in the supporting information).

While the start up behavior for the experiments conducted with a residence time of $0.5 \mathrm{~h}$ is similar (see supporting information), the transient behavior of the experiments performed with $\tau=1$ is significantly different. In Figure 8 we show the evolution of the solution concentration and mass fraction of $\beta$ polymorph for experiments $3_{\beta}, 7_{\alpha}$, and $7_{\beta}$, as well as $11_{\beta}, 15_{\alpha}$ and, $15_{\beta}$. Focussing first on the experiments at the lower feed concentration of 20 $\mathrm{g} \mathrm{kg}^{-1}$ (left panel), we observe that the solution concentration for the case without milling (exp. $3_{\beta}$, blue empty circles) goes through a maximum, whereas the cases with milling (exps. $7_{\alpha}$ (red filled circles) and $7_{\beta}$ (blue filled circles) ) do not. The steady state concentration for the experiments with milling is again (slightly) lower than in the experiment without milling. In terms of the mass fraction of $\beta$ polymorph, one can see that in the experiment without milling (exp. $3_{\beta}$; blue empty triangles) the $\beta$ crystals are again washed out quickly and $\alpha$ crystals prevail at steady state. However, remarkably, the mass fraction of $\beta$ polymorph for the experiment with milling and $\beta$ seeds (exp. $7_{\beta}$; blue filled triangles) stays at high mass fraction of $\beta$ polymorph for 8 residence times before $\alpha$ crystals start to nucleate and grow with the mass fraction of the $\beta$ polymorph rapidly decreasing. Performing an experiment at the same conditions, but with $\alpha$ seeds (exp. $7_{\alpha}$; red filled triangles), one can see that the process remains at almost pure $\alpha$ throughout. As discussed in the simulation part (see Figure 5 and text relating to it), the solution concentration can already be close to the final steady state concentration, even though the polymorph content can still change significantly, which is exemplified by these experiments. This shows again that for the crystallization of a polymorphic system it is of utmost importance to not only monitor the solution concentration to determine whether a process operates in steady state, but that one should also track the solid state composition. In the right panel of Figure 8 the results for the experiments carried out at the higher feed concentration of $30 \mathrm{~g} \mathrm{~kg}^{-1}$ are shown, which mirror the results obtained at the lower feed concentration. 

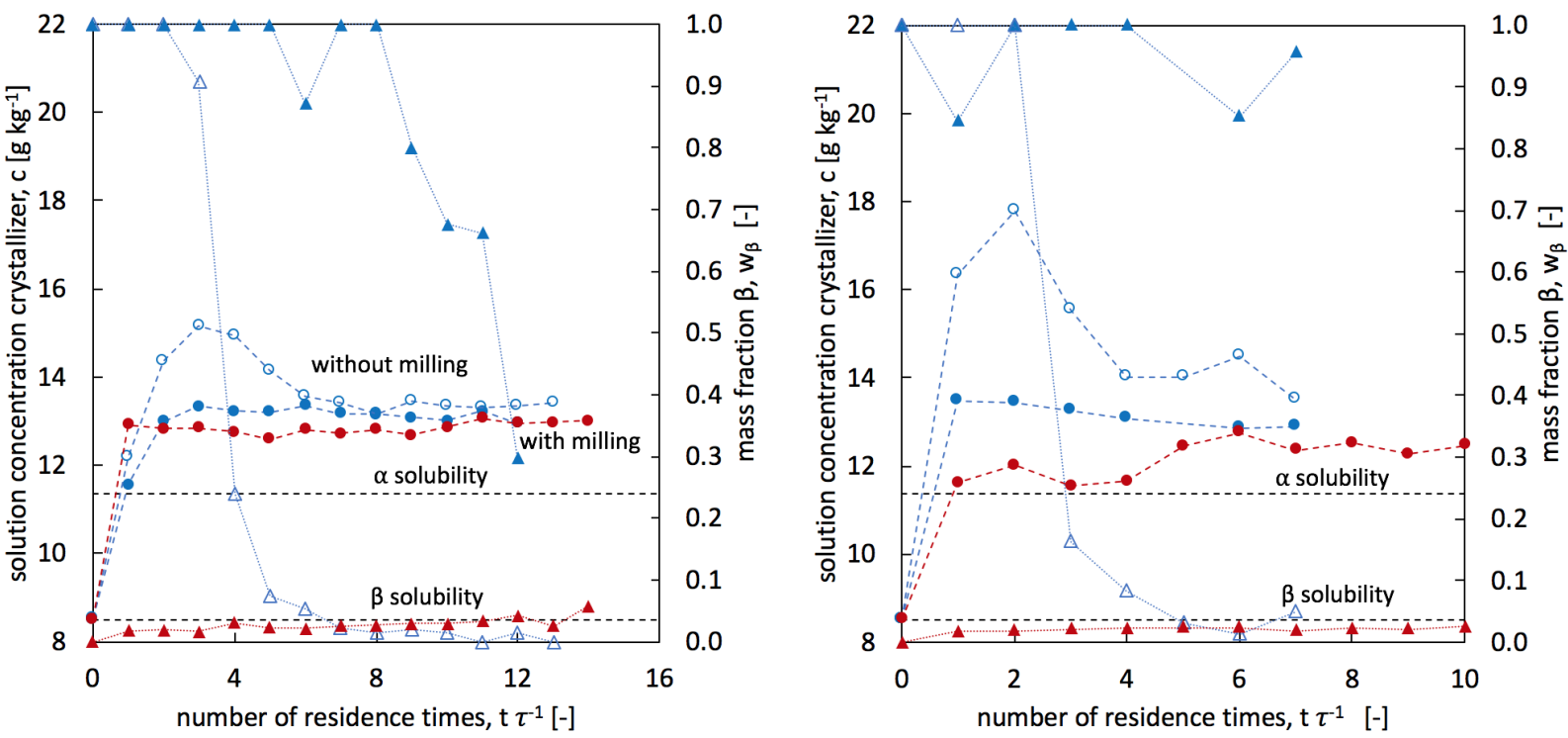

Figure 8: Evolution of solution concentration and mass fraction of $\beta$ polymorph observed for experiments conducted at a residence time $\tau=1 \mathrm{~h}$. (Left) Start Up of Exp. $3_{\beta}, 7_{\beta}$, and $7_{\alpha}$ at $c_{\text {in }}=20 \mathrm{~g} \mathrm{~kg}^{-1}$ and (Right) of Exp. $11_{\beta}, 15_{\beta}$, and $15_{\alpha}$ at $\mathrm{c}_{\mathrm{in}}=30 \mathrm{~g} \mathrm{~kg}^{-1}$. The $\alpha$ seeded experiments are drawn in red color; the beta seeded experiments in blue. On the left vertical axis the solution concentrations of the experiments without milling are drawn as empty circles (o); for experiments with milling as filled circles $(\bullet)$. The mass fraction of $\beta$ polymorph is given on the right vertical axis and is drawn for the experiment without milling as empty triangles $(\triangle)$ and for the experiments with milling as filled triangles $(\mathbf{\Delta})$. Lines drawn to guide the eye. 
Increasing the residence time further to $2 \mathrm{~h}$, the results reported in Figure 9 are obtained. The experiments were started, ran overnight, and samples were taken the next day, hence, only results at the beginning and after 12 or 18 hours of operation are reported. While the startup behavior of these experiments is therefore not fully resolved, the data allow extracting information about the steady state behavior. In the left panel of Figure 9, experiments carried out with a feed concentration of $20 \mathrm{~g} \mathrm{~kg}^{-1}$ are presented. The red filled symbols represent the experiment with milling, which was seeded with $\alpha$ crystals and the blue empty symbols represent the experiment carried out without milling, which was seeded with $\beta$ crystals. The results indicate that a complete polymorph change-over was enabled through the use of the mill: from the metastable $\alpha$ polymorph in the case without milling, to the stable $\beta$ polymorph in the case with milling. Notably, the steady state concentration for the experiment with milling is located below the solubility of the $\alpha$ polymorph; consequently, only crystals of the $\beta$ polymorph are obtained. The observation that the stable polymorph can be obtained through the use of milling at conditions that lead to the metastable polymorph without milling is in agreement with our simulation results reported in Figure 6. At the higher feed concentration of $30 \mathrm{~g} \mathrm{~kg}^{-1}$, this polymorph change-over is again observed, though, this time, the steady state concentration stays above the solubility of the $\alpha$ polymorph. Nevertheless, essentially pure $\beta$ polymorph is obtained.

Table 5 summarizes the steady state solution concentration, $\mathrm{c}_{\mathrm{ss}}$, the mass fraction of $\beta$ polymorph at steady state, $w_{\beta, \text { ss }}$, as well as the productivity obtained in all experiments. To determine the steady state values, the average of the last three measurement values was calculated. Summarizing the results, one can see that the steady state solution concentration decreases with increasing residence time (at constant feed concentration). The change in feed concentration affects the steady state concentration only slightly for the LGA/water case, which is consistent with the simulation results presented earlier. The experiments carried out with milling always exhibit a lower steady state concentration than the experiments without milling and hence using the mill allows reaching higher productivities. Therefore, 

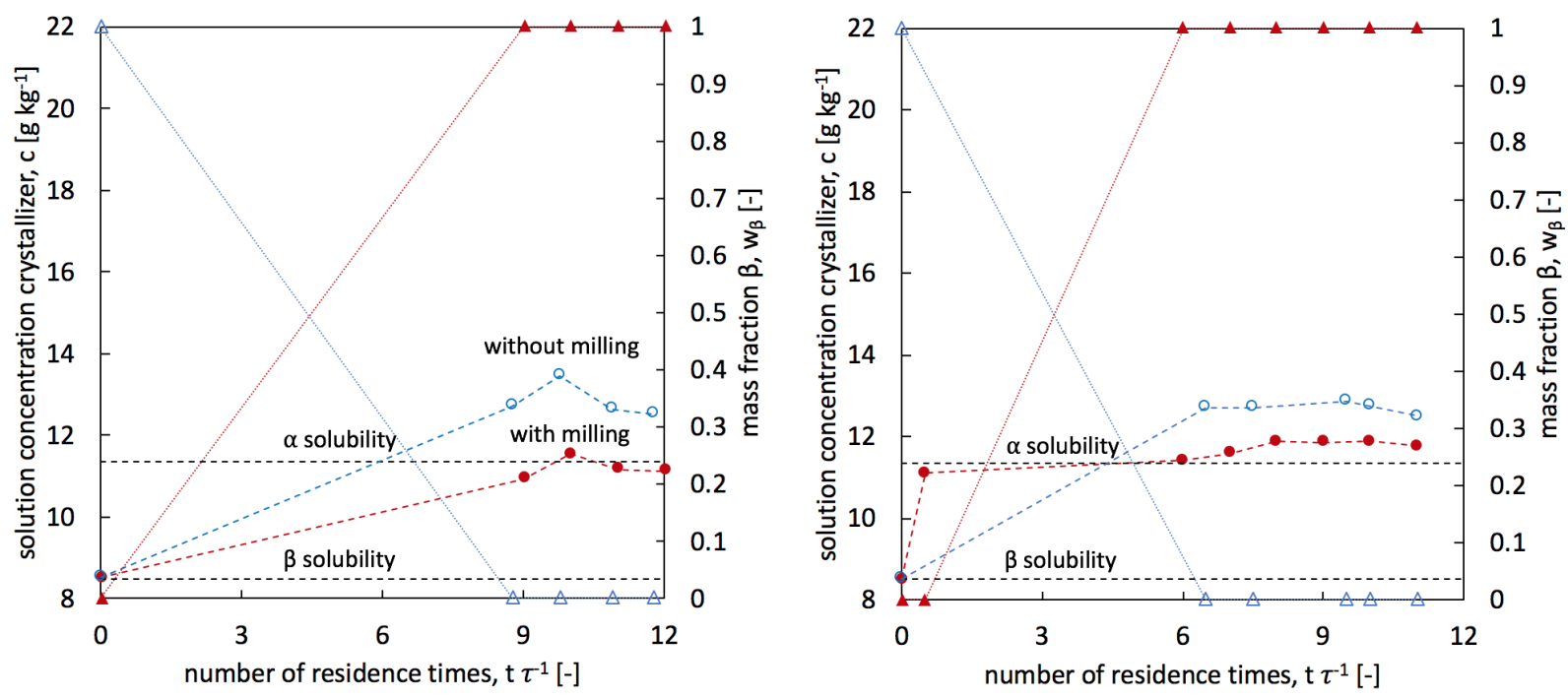

Figure 9: Evolution of solution concentration and mass fraction of $\beta$ polymorph observed for experiments conducted at a residence time $\tau=2 \mathrm{~h}$. (Left) Start Up of Exp. $4_{\beta}+8_{\alpha}$ at $\mathrm{c}_{\text {in }}=$ $20 \mathrm{~g} \mathrm{~kg}^{-1}$ and (Right) of Exp. $12_{\beta}+16_{\alpha}$ at $\mathrm{c}_{\mathrm{in}}=30 \mathrm{~g} \mathrm{~kg}^{-1}$. The $\alpha$ seeded experiment is drawn in red color; the $\beta$ seeded experiment in blue. The solution concentration of the experiments without milling are drawn as circles $(\circ)$, with milling as filled circles $(\bullet)$. The mass fraction of $\beta$ polymorph is given on the right vertical axis and is drawn for the experiment without milling as empty triangles $(\triangle)$ and for the experiments with milling as filled triangles $(\mathbf{\Delta})$. Lines drawn to guide the eye. 
apart from constituting a means to influence polymorphism at the steady state, milling is also shown to be an attractive tool for process intensification.

Table 5: Overview of steady state conditions achieved in all experiments

\begin{tabular}{llllrlrr}
\hline \multicolumn{2}{l}{ operating parameters } & \multicolumn{4}{l}{ without milling } \\
$\mathrm{c}_{\mathrm{in}}\left[\mathrm{g} \mathrm{kg}^{-1}\right]$ & $\tau[\mathrm{h}]$ & $\mathrm{c}_{\mathrm{ss}}\left[\mathrm{g} \mathrm{kg}^{-1}\right]$ & $w_{\beta, \mathrm{ss}}$ & $P\left[\mathrm{~kg} \mathrm{~m}^{-3} \mathrm{~h}^{-1}\right]$ & \multicolumn{2}{l}{ with milling } \\
\hline 20 & 0.25 & 15.8 & 0.01 & 16.8 & 13.4 & 0.01 & 26.4 \\
20 & 0.50 & 14.1 & 0.01 & 11.8 & 12.7 & 0.02 & 14.6 \\
20 & 1.00 & 13.4 & 0.00 & 6.6 & 13.0 & $0.0 \mathrm{gg}^{\dagger}$ & 7.0 \\
20 & 2.00 & 13.1 & 0.00 & 3.5 & 11.3 & 1.00 & 4.4 \\
30 & 0.25 & 15.6 & 0.00 & 57.6 & 13.6 & 0.00 & 65.6 \\
30 & 0.50 & 14.1 & 0.01 & 31.8 & 13.2 & 0.05 & 33.6 \\
30 & 1.00 & 13.5 & 0.03 & 16.5 & 12.9 & $0.02^{\dagger}$ & 17.1 \\
30 & 2.00 & 12.7 & 0.00 & 8.7 & 11.8 & 1.00 & 9.1 \\
\hline
\end{tabular}

$\dagger$ The value reported refers to the experiment seeded with $\alpha$ crystals, i.e., the polymorph present at the stable steady state.

\section{Concluding Remarks}

In this work, we have conducted an experimental and modelling study on a continuous crystallization-milling process, where we have investigated the crystallization of LGA from water. Investigating the start-up of the process in our model, we have concluded that (i) steady state multiplicity exists and (ii) that different steady states are accessible through seeding; confirming earlier results conducted on processes without milling ${ }^{11,33}$. However, it should be pointed out that this finding is a consequence of using specific nucleation kinetics in the model (no primary nucleation and at least one form without cross-nucleation, i.e., where secondary nucleation kinetics of one form do not depend on the presence of the other form). Such steady states are dynamically unstable, i.e., the system departs from them and moves towards the stable steady state when slight disturbances are introduced (such as a primary nucleation event or the addition of a form impure seed material). By seeding exclusively with the polymorph that does not dominate at the stable steady state in our experimental campaign, we have intentionally shown that such steady states can be quite long-lived (see 
Figure 8 where the unstable steady state is visible for roughly 8 residence times). Operation at such unstable steady states is generally not advisable from the viewpoint of process robustness (unless suitable measurement and control strategies are put in place). In order to reliably identify the stable steady state at given process conditions, we therefore recommend to use seed material that is a mixture of polymorphic forms.

In terms of results obtained at stable steady states, we have shown that the use of a rotor stator mill for crystal breakage leads to an increase of productivity. Mechanistically, this effect can be understood as the result of milling decreasing the size of crystals present and therefore increasing their surface area (at constant mass). This, in turn, increases the mass deposition rate of the solute on to the crystals. It should be noted, however, that this relies on the mill being appropriately temperature-controlled. If this were not the case, the temperature of the process stream leaving the mill would be increased, possibly leading to the partial dissolution of particles. If intense milling is used, there is also a risk of amorphization and a risk to induce solid state transformations ${ }^{57}$. However, in the experimental case study on LGA crystallized from water presented here, we did not observe such effects (see pXRD data in the supporting information). Indeed, we have shown that even mild/moderate milling conditions can be successfully applied to increase the productivity of the process. It is noteworthy that we were able to qualitatively describe our experimental observations using a process model that solely relies on nucleation, crystal growth and breakage, i.e., no specific alterations in the model structure were necessary to account for the energy input of the mill into the suspension.

We have also shown that milling can be used as a tool to steer the polymorphic outcome of a continuous crystallization process. For the case of LGA crystallized from water, we have shown that it becomes possible to obtain the stable polymorph at high productivity under processing conditions that would lead to the metastable polymorph without the mill, see Figure 9. In previous work, Lai et al. ${ }^{11}$ predicted that the stable polymorph can only be crystallized in a single MSMPRC set up with residence times exceeding $17.4 \mathrm{~h}$ at 
$25^{\circ} \mathrm{C}$ and a feed concentration of $40 \mathrm{~g} \mathrm{~kg}^{-1}$. In contrast, our results show that a combined milling-crystallization process produces the stable polymorph already at a residence time of two hours. Despite having to use a lower feed concentration (due to LGA degradation at high temperatures, see supporting information), this constitutes a roughly 6-fold increase in production rate of the stable polymorph. This effect can be understood as a consequence of increasing the rate of formation of new crystals. Without milling (primary and secondary) nucleation constitutes the only source of new particles in the process; by introducing milling to the process, the particle generation rate can be increased and, importantly, it can be increased in a targeted fashion.

While crystal breakage consistently steered the process towards the stable polymorph in our experiments and the process simulations on LGA, we have not studied whether this is a general phenomenon that is applicable to other substances. However, we note that the breakage rate of crystals in general depends on the mechanical properties of the crystal form, as well as their size and shape (intuitively, everything else being equal, it is easier to break long, thin objects, rather than compact crystals). Both these properties may differ substantially for different polymorphs/crystal forms. If the goal is to steer the process towards the stable polymorph, the case of LGA may be fortunate in this respect, because the stable polymorph exhibits a needle-like morphology that may be more prone to breakage than the metastable polymorph that exhibits a prismatic morphology. On the other hand, increasing the surface area of the crystal suspension will always lower the steady state concentration and will therefore tend to favor the stable polymorph. In an upcoming work we have investigated the relationship between different breakage rates of polymorphs and the polymorphic outcome of a crystallization-milling processing in more depth and the interested reader is referred to that work ${ }^{58}$. 


\section{Acknowledgement}

TK thanks The University of Manchester for providing a PhD scholarship. TV thanks the Royal Academy of Engineering for support through an Engineering for Development research fellowship (RF1516 $\backslash 15 \backslash 22)$.

\section{Supporting Information Available}

The supporting information contains additional details about about the experimental setup (photographs, pump operation), additional simulation results with alternative LGA crystallization kinetics, differential scanning calorimetry results regarding LGA degradation at elevated temperature, and details about the calibration to determine polymorphic content using pXRD data. It also contains figures reporting the start up behavior of the process in the experiments with 30 minutes residence time, microscopy pictures taken during the start up of many experiments, as well as a comprehensive notation table.

\section{References}

(1) Chemburkar, S. R.; Bauer, J.; Deming, K.; Spiwek, H.; Patel, K.; Morris, J.; Henry, R.; Spanton, S.; Dziki, W.; Porter, W. Dealing with the impact of ritonavir polymorphs on the late stages of bulk drug process development. Org. Process Res. Dev. 2000, 4 , $413-417$.

(2) Bernstein, J. Polymorphism in molecular crystals; IUCr Monographs on Crystallography; Oxford Science Publications, 2002; Vol. 14.

(3) Brittain, H. G. Polymorphism in pharmaceutical solids; CRC Press: Boca Raton FL, USA, 2009. 
(4) Wieckhusen, D. The Development of API Manufacturing Processes-Targets and Strategies. Chimia 2006, 60, 598-604.

(5) Borissova, A.; Khan, S.; Mahmud, T.; Roberts, K. J.; Andrews, J.; Dallin, P.; Chen, Z.P.; Morris, J. In situ measurement of solution concentration during the batch cooling crystallization of L-glutamic acid using ATR-FTIR spectroscopy coupled with chemometrics. Cryst. Growth Des. 2008, 9, 692-706.

(6) Cardew, P. T.; Davey, R. J. The kinetics of solvent-mediated phase transformations. Proc. R. Soc. Lond. 1985, 398, 415-428.

(7) Kitamura, M. Polymorphism in the crystallization of L-glutamic acid. J. Cryst. Growth 1989, 96, 541-546.

(8) Dharmayat, S.; De Anda, J. C.; Hammond, R. B.; Lai, X.; Roberts, K. J.; Wang, X. Z. Polymorphic transformation of L-glutamic acid monitored using combined on-line video microscopy and X-ray diffraction. J. Cryst. Growth 2006, 294, 35-40.

(9) Cornel, J.; Lindenberg, C.; Mazzotti, M. Experimental characterization and population balance modeling of the polymorph transformation of L-glutamic acid. Cryst. Growth Des. 2008, 9, 243-252.

(10) Jia, C.-Y.; Yin, Q.-X.; Zhang, M.-J.; Wang, J.-K.; Shen, Z.-H. Polymorphic transformation of pravastatin sodium monitored using combined online FBRM and PVM. Org. Process Res. Dev. 2008, 12, 1223-1228.

(11) Lai, T.-T. C.; Ferguson, S.; Palmer, L.; Trout, B. L.; Myerson, A. S. Continuous Crystallization and Polymorph Dynamics in the L-Glutamic Acid System. Org. Process Res. Dev. 2014, 18, 1382-1390.

(12) Manzurola, E.; Apelblat, A. Solubilities of L-glutamic acid, 3-nitrobenzoic acid, p-toluic 
acid, calcium-L-lactate, calcium gluconate, magnesium-DL-aspartate, and magnesiumL-lactate in water. J. Chem. Thermodyn. 2002, 34, 1127-1136.

(13) Mo, Y.; Dang, L.; Wei, H. Solubility of $\alpha$-form and $\beta$-form of L-glutamic acid in different aqueous solvent mixtures. Fluid Phase Equilib. 2011, 300, 105-109.

(14) Schaber, S.; Gerogiorgis, D.; Ramachandran, R.; Evans, J.; Barton, P.; Trout, B. Economic Analysis of Integrated Continuous and Batch Pharmaceutical Manufacturing: A Case Study. Ind. Eng. Chem. Res. 2011, 50, 10083-10092.

(15) Poechlauer, P.; Colberg, J.; Fisher, E.; Jansen, M.; Johnson, M.; Koenig, S.; Lawler, M.; Laporte, T.; Manley, J.; Martin, B.; O'Kearney-McMullan, A. Pharmaceutical Roundtable Study Demonstrates the Value of Continuous Manufacturing in the Design of Greener Processes. Org. Process Res. Dev. 2013, 17, 1472-1478.

(16) Vetter, T.; Burcham, C.; Doherty, M. Regions of attainable particle sizes in continuous and batch crystallization processes. Chem. Eng. Sci. 2014, 106, 167-180.

(17) Lakerveld, R.; Benyahia, B.; Heider, P.; Zhang, H.; Wolfe, A.; Testa, C.; Ogden, S.; Hersey, D.; Mascia, S.; Evans, J.; Braatz, R.; Barton, P. The Application of an Automated Control Strategy for an Integrated Continuous Pharmaceutical Pilot Plant. Org. Process Res. Dev. 2015, 19, 1088-1100.

(18) Lee, C.; Khoo, H.; Tan, R. Life Cyle Assessment Based Environmental Performance Comparison of Batch and Continuous Processing: A Case of 4-d-Erythronolactone Synthesis. Org. Process Res. Dev. 2016, 20, 1937-1948.

(19) Diab, S.; Gerogiorgis, D. Technoeconomic Evaluation of Multiple Mixed SuspensionMixed Product Removal (MSMPR) Crystallizer Configurations for Continuous Cyclosporine Crystallization. Org. Process Res. Dev. 2017, 21, 1571-1587. 
(20) Yang, X.; Acevedo, D.; Mohammad, A.; Pavurala, N.; Wu, H.; Brayton, A.; Shaw, R.; Goldman, M.; He, F.; Li, S.; Fisher, R.; O’Connor, T.; Cruz, C. Risk Considerations on Developing a Continuous Crystallization System for Carbamazepine. Org. Process Res. Dev. 2017, 21, 1021-1033.

(21) Lawton, S.; Steele, G.; Shering, P.; Zhao, L.; Laird, I.; Ni, X.-W. Continuous Crystallization of Pharmaceuticals Using a Continuous Oscillatory Baffled Crystallizer. Org. Process Res. Dev. 2009, 13, 1357-1363.

(22) Eder, R.; Radl, S.; Schmitt, E.; Innerhofer, S.; Maier, M.; Gruber-Woelfler, H.; Khinast, J. Continuously Seeded, Continuously Operated Tubular Crystallizer for the Production of Active Pharmaceutical Ingredients. Cryst. Growth Des. 2010, 10, 2247-2257.

(23) Jiang, M.; Zhu, Z.; Jimenez, E.; Papageorgiou, C.; Waetzig, J.; Hardy, A.; Langston, M.; Braatz, R. Continuous-Flow Tubular Crystallization in Slugs Spontaneously Induced by Hydrodynamics. Cryst. Growth Des. 2014, 14, 851-860.

(24) Briggs, N.; Schacht, U.; Raval, V.; McGlone, T.; Sefcik, J.; Florence, A. Seeded Crystallization of $\beta$-L-Glutamic Acid in a Continuous Oscillatory Baffled Crystallizer. Org. Process Res. Dev. 2015, 19, 1903-1911.

(25) McGlone, T.; Briggs, N.; Clark, C.; Brown, C.; Sefcik, J.; Florence, A. J. Oscillatory flow reactors (OFRs) for continuous manufacturing and crystallization. Org. Process Res. Dev. 2015, 19, 1186-1202.

(26) Robertson, K.; Flandrin, P.-B.; Klapwijk, A.; Wilson, C. Design and Evaluation of a Mesoscale Segmented Flow Reactor (KRAIC). Cryst. Growth Des. 2016, 16, 47594764.

(27) Besenhard, M.; Neugebauer, P.; Scheibelhofer, O.; Khinast, J. G. Crystal Engineering in Continuous Plug-Flow Crystallizers. Cryst. Growth Des. 2017, 17, 6432-6444. 
(28) Wiedmeyer, V.; Anker, F.; Bartsch, C.; Voigt, A.; John, V.; Sundmacher, K. Continuous Crystallization in a Helically Coiled Flow Tube: Analysis of Flow Field, Residence Time Behavior, and Crystal Growth. Ind. Eng. Chem. Res. 2017, 56, 3699-3712.

(29) Vetter, T.; Burcham, C.; Doherty, M. Designing robust crystallization processes in the presence of parameter uncertainty using attainable regions. Ind. Eng. Chem. Res. 2015, 54, 10350-10363.

(30) Yang, Y.; Song, L.; Nagy, Z. Automated Direct Nucleation Control in Continuous Mixed Suspension Mixed Product Removal Cooling Crystallization. Cryst. Growth Des. 2015, $15,5839-5848$.

(31) Li, J.; Trout, B.; Myerson, A. Multistage Continuous Mixed-Suspension, Mixed-Product Removal (MSMPR) Crystallization with Solids Recycle. Org. Process Res. Dev. 2016, 20, 510-516.

(32) Lai, T.-T. C.; Cornevin, J.; Ferguson, S.; Li, N.; Trout, B. L.; Myerson, A. S. Control of Polymorphism in Continuous Crystallization via Mixed Suspension Mixed Product Removal Systems Cascade Design. Cryst. Growth Des. 2015, 15, 3374-3382.

(33) Farmer, T. C.; Carpenter, C. L.; Doherty, M. F. Polymorph Selection by Continuous Crystallization. AIChE J. 2016, 62, 3505-3514.

(34) Agnew, L. R.; McGlone, T.; Wheatcroft, H. P.; Robertson, A.; Parsons, A. R.; Wilson, C. C. Continuous Crystallization of Paracetamol (Acetaminophen) Form II: Selective Access to a Metastable Solid Form. Cryst. Growth Des. 2017, 17, 2418-2427.

(35) Lehmann, M. S.; Nunes, A. C. A short hydrogen bond between near identical carboxyl groups in the $\alpha$-modification of L-glutamic acid. Acta Crystallographica Section B: Structural Crystallography and Crystal Chemistry 1980, 36, 1621-1625. 
(36) Hirokawa, S. A new modification of L-glutamic acid and its crystal structure. Acta Crystallographica 1955, 8, 637-641.

(37) Schöll, J.; Bonalumi, D.; Vicum, L.; Mazzotti, M.; Müller, M. In situ monitoring and modeling of the solvent-mediated polymorphic transformation of L-glutamic acid. Cryst. Growth Des. 2006, 6, 881-891.

(38) Lindenberg, C.; Schöll, J.; Vicum, L.; Mazzotti, M.; Brozio, J. L-glutamic acid precipitation: agglomeration effects. Cryst. Growth Des. 2008, 8, 224-237.

(39) Hermanto, M. W.; Chiu, M. S.; Braatz, R. D. Nonlinear Model Predictive Control for the Polymorphic Transformation of L-Glutamic Acid Crystals. AIChE J. 2009, 55, $2631-2645$.

(40) Ochsenbein, D.; Schorsch, S.; Vetter, T.; Mazzotti, M.; Morari, M. Growth Rate Estimation of $\beta$ L-Glutamic Acid from Online Measurements of Multidimensional Particle Size Distributions and Concentration. Ind. Eng. Chem. Res. 2014, 53, 9136-9148.

(41) Su, Q.; Rielly, C. D.; Powell, K. A.; Nagy, Z. K. Mathematical modelling and experimental validation of a novel periodic flow crystallization using MSMPR crystallizers. AIChE J. 2017, 63, 1313-1327.

(42) Randolph, A. D.; Larson, M. A. Theory of Particulate Processes; Academic Press: San Diego CA, USA, 1988.

(43) Ramkrishna, D. Population Balances; Academic Press: Cambridge MA, USA, 2000.

(44) Qamar, S.; Elsner, M.; Angelov, I.; Warnecke, G.; Seidel-Morgenstern, A. A comparative study of high resolution schemes for solving population balances in crystallization. Comput. Chem. Eng. 2006, 30, 1119-1131.

(45) Koren, B. A robust upwind discretization method for advection, diffusion and source terms; Notes on numerical fluid mechanics; Vieweg Verlag, 1993; Vol. 45; pp 117-138. 
(46) Kumar, S.; Ramkrishna, D. On the solution of population balance equations by discretization-I. A fixed pivot technique. Chem. Eng. Sci. 1996, 51, 1311-1332.

(47) Shampine, L.; Reichelt, M. The MATLAB ODE Suite. SIAM J. Sci. Comput. 1997, $18,1-22$.

(48) Schöll, J.; Lindenberg, C.; Vicum, L.; Brozio, J.; Mazzotti, M. Precipitation of alpha L-glutamic acid: determination of growth kinetics. Faraday Discussions 2007, 136, $247-264$.

(49) Salvatori, F.; Mazzotti, M. Experimental Characterization and Mathematical Modeling of Breakage of Needle-like Crystals in a Continuous Rotor-Stator Wet Mill. Cryst. Growth Des. 2018, 18, 5957-5972.

(50) Iggland, M.; Mazzotti, M. A Population Balance Model for Chiral Resolution via Viedma Ripening. Cryst. Growth Des. 2011, 11, 4611-4622.

(51) Vetter, T.; Burcham, C.; Doherty, M. Separation of conglomerate forming enantiomers using a novel continuous preferential crystallization process. AIChE J. 2015, 61, 28102823.

(52) Köllges, T.; Vetter, T. Model-based analysis of continuous crystallization/reaction processes separating conglomerate forming enantiomers. Cryst Growth Des. 2017, 17, 233247.

(53) Köllges, T.; Vetter, T. Design and Performance Assessment of Continuous Crystallization Processes Resolving Racemic Conglomerates. Cryst. Growth Des. 2018, 18, $1686-1696$.

(54) Luciani, C. V.; Conder, E. W.; Seibert, K. D. Modeling-Aided Scale-Up of High-Shear Rotor-Stator Wet Milling for Pharmaceutical Applications. Org. Process Res. Dev. 2015, 19, 582-589. 
(55) Farmer, T.; Schiebel, S.; Chmelka, B.; Doherty, M. Polymorph Selection by Continuous Precipitation. Cryst. Growth Des. 2018, 18, 4306-4319.

(56) Hunter, J. D. Matplotlib: A 2D graphics environment. Computing In Science \& Engineering 2007, 9, 90-95.

(57) Descamps, M.; Willart, J. Perspectives on the amorphisation/milling relationship in pharmaceutical materials. Advanced Drug Delivery Reviews 2016, 100, 51-66.

(58) Li, Y.; O’Shea, S.; Yin, Q.; Vetter, T. Polymorph selection by continuous crystallization in the presence of wet milling. submitted 